The Egyptian Journal of Hospital Medicine (January 2021) Vol. 82 (4), Page 714-718

\title{
Role of Cranial Ultrasound in High-Risk Full-Term Neonates
}

Ghada S. Abdelmotaleb, Ahmed M. Soliman*, Neveen T. Abed

Department of Pediatric, Faculty of Medicine, Benha University, Egypt

*Corresponding author: Ahmed M. Soliman, Mobile: (+20) 01008139738, E-Mail: mohamed.soliman.marie@gmail.com

\begin{abstract}
Background: Critically ill full-term infants are at risk for brain injury. The improvement of the survival of the "High-Risk Neonate" requires early detection of neurological abnormalities. Cranial ultrasonography (CUS) is the preferred tool to study the neonatal brain.

Objective: This study aimed to evaluate the diagnostic role of cranial US in high-risk full-term neonates.

Patients and Methods: This observational study was conducted on 60 high-risk full-term neonates randomly selected from the Neonatal Intensive Care Unit, Pediatric Department, Benha University Hospitals. Detailed history, clinical examination, appropriate investigations and cranial ultrasound were done.

Results: The cranial ultrasound findings were normal in 58 cases (96.7\%) and abnormal only in 2 cases $(3.3 \%)$. The cranial ultrasound abnormalities found in the first case that was diagnosed as hypoxic ischemic encephalopathy and congenital malformation were hypoplasia of the cerebellar hemispheres, dilated fourth ventricle and prominent cisterna magna with Dandy walker malformation. The second case who was diagnosed as pneumonia and neonatal sepsis, cranial sonography showed cystic leukomalacia and communicating hydrocephalus.

Conclusion: Although we found only 2 cases (3.3\%) with abnormal CUS among the studied high-risk full-term neonates, cranial ultrasound is considered an important noninvasive method for brain imaging in neonates especially in those presented with neurological manifestations or exposed to hypoxia. It enables screening and follow up of the brain by serial imaging.
\end{abstract}

Keywords: Cranial ultrasound, NICU, High-risk neonates.

\section{INTRODUCTION}

Any neonate, regardless of gestational age, who has a greater chance of morbidity and mortality, especially within the first 28 days of life, is classified as high-risk neonate. CUS plays an important role in assessing neurological outcome among them ${ }^{(1)}$. CUS has numerous advantages: it can be performed at the bedside, it is relatively safe, and can be repeated when needed, helping visualization of ongoing brain maturation and the evolution of lesions. It detects most of the hemorrhagic, ischemic, cystic brain lesions, calcifications, major congenital abnormalities and cerebral infections ${ }^{(2)}$. It is also important in the early diagnosis of numerous causes of neonatal seizures and encephalopathy in full-term neonates and the subsequent follow up of hypoxicischemic brain injury ${ }^{(3)}$. CUS examination should be performed soon after birth and further examinations depending on clinical symptoms and previous CUS findings in critically ill full-term neonates and fullterm neonates with congenital anomalies ${ }^{(4)}$.

Benson et al. ${ }^{(5)}$ reported that sonography of the brain is now an integral part of care in the neonate, among unstable premature and high-risk infant. Therefore, this study aimed to evaluate the diagnostic value of CUS in high-risk full-term neonates.

\section{PATIENTS AND METHODS}

This study was conducted on 60 high-risk fullterm neonates randomly selected from the Neonatal Intensive Care Unit (NICU), Pediatric Department at Benha University Hospitals, in the a period from January 2019 to January 2020.

Ethical approval: Approval of the Research Ethics Committee at Faculty of Medicine, Benha University Hospital was obtained. A written consent was collected from neonates' parents to agree to participate in the study.

High-risk full-term neonates with any of the following diagnosis were included in the study: neonatal convulsions, birth asphyxia, hypoxic ischemic encephalopathy (HIE), respiratory distress, neonatal sepsis or metabolic abnormalities.

\section{All patients were subjected to the following:}

Full perinatal history was taken. Thorough clinical examination with special emphasis on neurological manifestations was done. Routine investigations (CBC, CRP) and cranial ultrasound of these high-risk neonates were done. Neonates were followed up till discharge from NICU.

The sonograms were performed on a Voluson 630 pro GE machine using a multi frequency high-

This article is an open access article distributed under the terms and conditions of the Creative Commons Attribution (CC BY-SA) license (http://creativecommons.org/licenses/by/4.0/) 
density volume -TV/TR probe. All ultrasounds were performed by the same physician to avoid interobserver variation

Statistical Analysis: Descriptive statistical analysis was carried out. Results on continuous measurements were presented as mean \pm SD (MinMax) and results on categorical measurements were presented in Number (\%). Chi-square/Fisher Exact test was used to find the significance of study parameters on categorical scale between two groups. Student " $t$ " test compares between 2 means of 2 independent groups. A significant $p$-value was considered when it is equal or less than 0.05 .

\section{RESULTS}

This study included 60 term high risk neonates, $39(65 \%)$ were males and $21(35 \%)$ were females. Their gestational age ranged from 37 to 39 weeks with a mean of $37.78 \pm 0.83$ weeks, and their birth weight ranged from 2.9 to $4 \mathrm{~kg}$ with a mean of 3.16 $\pm 0.24 \mathrm{~kg}$. Mode of delivery was normal in 17 cases and Cesarean section (CS) in 43 cases (Table 1).
Both cases with abnormal CUS were delivered normal. The incidence of CUS abnormalities in highrisk neonates was $3.3 \%$ (Table 2).

The abnormal CUS findings in the cases were $1^{\text {st }}$ case with pneumonia and neonatal sepsis, CUS showed cystic leukomalacia associated with communicating hydrocephalus, this case survived. $2^{\text {nd }}$ case with hypoxic ischemic encephalopathy (HIE) and congenital malformation, CUS showed hypoplasia of the cerebellar hemispheres, dilated fourth ventricle and prominent cisterna magna with Dandy walker malformation, this case died. There was no statistically significant difference between abnormal CUS and normal CUS groups regarding perinatal history (Tables 3, 4 \& 5).

There was no statistically significant difference between abnormal CUS and normal CUS groups regarding different clinical presentations except highly significant presence of hypoxia among abnormal CUS group than normal CUS group (Table $6)$.

Table (1): Demographic data of the studied cases

\begin{tabular}{|c|c|c|c|}
\hline & & \multicolumn{2}{|c|}{ Mean \pm SD } \\
\hline \multicolumn{2}{|c|}{ Gestational age ( Weeks ) } & \multicolumn{2}{|c|}{$37.78 \pm 0.83$} \\
\hline \multicolumn{2}{|c|}{ Birth weight(kg) } & \multicolumn{2}{|c|}{$3.16 \pm 0.24$} \\
\hline & & No. (60) & $\%$ \\
\hline \multirow{2}{*}{ Sex } & Male & 39 & 65.0 \\
\hline & Female & 21 & 35.0 \\
\hline \multirow{2}{*}{ Mode of delivery } & NVD & 17 & 28.3 \\
\hline & CS & 43 & 71.7 \\
\hline
\end{tabular}

NVD: Normal vaginal delivery CS: cesarean section

Table (2): C.U.S. of the studied cases.

\begin{tabular}{|c|c|c|c|}
\hline \multicolumn{2}{|c|}{} & No. & \% \\
\hline \multirow{2}{*}{ CUS } & Normal & 58 & 96.7 \\
\cline { 2 - 4 } & Abnormal & 2 & 3.3 \\
\hline
\end{tabular}

Table (3): Comparison between abnormal C.U.S. and normal C.U.S. groups regarding prenatal history

\begin{tabular}{|c|c|c|c|c|c|}
\hline & & $\begin{array}{c}\text { Abnormal } \\
\text { C.U.S No (\%) }\end{array}$ & $\begin{array}{c}\text { Normal C.U.S } \\
\text { No }(\%)\end{array}$ & $\mathbf{X}^{2}$ & P. value \\
\hline \multirow{2}{*}{ Diabetes mellitus } & Yes & $0(0 \%)$ & $3(5.2 \%)$ & \multirow{2}{*}{0.109} & \multirow{2}{*}{0.741} \\
\hline & No & $2(100 \%)$ & $55(94.8 \%)$ & & \\
\hline \multirow{2}{*}{$\begin{array}{c}\text { Maternal fever } \\
\text { above } 38\end{array}$} & Yes & $1(50.0 \%)$ & $5(8.6 \%)$ & \multirow{2}{*}{3.678} & \multirow{2}{*}{0.055} \\
\hline & No & $1(50.0 \%)$ & $53(91.4 \%)$ & & \\
\hline \multirow{2}{*}{$\begin{array}{l}\text { Maternal urinary } \\
\text { tract infection }\end{array}$} & Yes & $0(.0 \%)$ & $7(12.1 \%)$ & \multirow{2}{*}{0.273} & \multirow{2}{*}{0.601} \\
\hline & No & $2(100 \%)$ & $51(87.9 \%)$ & & \\
\hline
\end{tabular}


Table (4): Comparison between abnormal C.U.S. and normal C.U.S. groups regarding natal history

\begin{tabular}{|c|c|c|c|c|c|}
\hline & & $\begin{array}{c}\text { Abnormal C.U.S } \\
\text { No (\%) }\end{array}$ & $\begin{array}{c}\text { Normal C.U.S } \\
\text { No }(\%) \\
\end{array}$ & $\mathrm{X}^{2}$ & P. value \\
\hline \multirow{2}{*}{$\begin{array}{c}\text { Premature rapture of } \\
\text { membrane }\end{array}$} & Yes & $0(.0 \%)$ & $8(13.8 \%)$ & \multirow{2}{*}{$\begin{array}{c}\mathbf{F E} \\
0.318 \\
\end{array}$} & \multirow{2}{*}{0.573} \\
\hline & No & $2(100.0 \%)$ & $50(86.2 \%)$ & & \\
\hline \multirow{2}{*}{ Maternal fever } & Yes & $0(.0 \%)$ & $3(5.2 \%)$ & \multirow{2}{*}{$\begin{array}{c}\mathbf{F E} \\
0.109 \\
\end{array}$} & \multirow{2}{*}{0.741} \\
\hline & No & $2(100.0 \%)$ & $55(94.8 \%)$ & & \\
\hline \multirow{2}{*}{$\begin{array}{c}\text { Prolonged 2nd stage } \\
\text { of labor }\end{array}$} & Yes & $0(.0 \%)$ & $4(6.9 \%)$ & \multirow{2}{*}{$\begin{array}{c}\mathbf{F E} \\
0.148 \\
\end{array}$} & \multirow{2}{*}{0.701} \\
\hline & No & $2(100.0 \%)$ & $54(93.1 \%)$ & & \\
\hline
\end{tabular}

Table (5): Comparison between abnormal C.U.S. and normal C.U.S. groups regarding postnatal history

\begin{tabular}{|c|c|c|c|c|c|c|}
\hline & & & $\begin{array}{c}\text { Abnormal } \\
\text { C.U.S }\end{array}$ & $\begin{array}{c}\text { Normal } \\
\text { C.U.S } \\
\end{array}$ & $\mathbf{X}^{2}$ & P. value \\
\hline Apgar score at $1 \mathrm{~m}$ & \multicolumn{2}{|c|}{ Mean \pm SD } & $5.50 \pm 0.71$ & $5.48 \pm 0.50$ & $\begin{array}{c}\text { t. test } \\
.047 \\
\end{array}$ & 0.963 \\
\hline Apgar score at 5 m & \multicolumn{2}{|c|}{ Mean \pm SD } & $8.50 \pm 0.71$ & $7.95 \pm 0.87$ & $\begin{array}{c}\text { t. test } \\
.887\end{array}$ & 0.379 \\
\hline \multirow{2}{*}{ Respiratory distress } & Yes & No. $(\%)$ & $2(100.0 \%)$ & $28(48.3 \%)$ & \multirow{2}{*}{$\begin{array}{c}\mathbf{F E} \\
2.069\end{array}$} & \multirow{2}{*}{0.150} \\
\hline & No & No. $(\%)$ & $0(.0 \%)$ & $30(51.7 \%)$ & & \\
\hline \multirow{2}{*}{ Cyanosis } & Yes & No. $(\%)$ & $0(.0 \%)$ & $2(3.4 \%)$ & \multirow{2}{*}{$\begin{array}{c}\mathbf{F E} \\
0.071 \\
\end{array}$} & \multirow{2}{*}{0.789} \\
\hline & No & No. $(\%)$ & $2(100.0 \%)$ & $56(96.6 \%)$ & & \\
\hline \multirow{2}{*}{ Jaundice } & Yes & No. (\%) & $0(.0 \%)$ & $17(29.3 \%)$ & \multirow{2}{*}{$\begin{array}{c}\mathbf{F E} \\
0.818 \\
\end{array}$} & \multirow{2}{*}{0.366} \\
\hline & No & No. $(\%)$ & $2(100.0 \%)$ & $41(70.7 \%)$ & & \\
\hline
\end{tabular}

Table (6): Clinical examination among abnormal C.U.S. versus normal C.U.S. groups

\begin{tabular}{|c|c|c|c|c|c|}
\hline & & $\begin{array}{c}\text { Abnormal } \\
\text { C.U.S } \\
\text { No (\%) } \\
\end{array}$ & $\begin{array}{c}\text { Normal } \\
\text { C.U.S } \\
\text { No }(\%) \\
\end{array}$ & $\mathbf{X}^{2}$ & $\begin{array}{c}\text { P. } \\
\text { value }\end{array}$ \\
\hline \multirow{2}{*}{ Clinical signs of sepsis } & Yes & $1(50.0 \%)$ & $35(60.3 \%)$ & \multirow{2}{*}{.086} & \multirow{2}{*}{0.769} \\
\hline & No & $1(50.0 \%)$ & $23(39.7 \%)$ & & \\
\hline \multirow{2}{*}{ Hypoxia } & Yes & $2(100 \%)$ & $5(8.6 \%)$ & \multirow{2}{*}{$\begin{array}{c}\text { FE } \\
15.665\end{array}$} & \multirow{2}{*}{0.000} \\
\hline & No & $0(0 \%)$ & $53(91.4 \%)$ & & \\
\hline \multirow{2}{*}{ Increased oxygen requirement } & Yes & $2(100 \%)$ & $28(48.3 \%)$ & \multirow{2}{*}{$\begin{array}{c}\mathbf{F E} \\
2.069\end{array}$} & \multirow{2}{*}{0.150} \\
\hline & No & $0(0 \%)$ & $30(51.7 \%)$ & & \\
\hline \multirow{2}{*}{ Signs of respiratory distress } & Yes & $2(100 \%)$ & $28(48.3 \%)$ & \multirow{2}{*}{$\begin{array}{c}\mathbf{F E} \\
2.069\end{array}$} & \multirow{2}{*}{0.150} \\
\hline & No & $0(0 \%)$ & $30(51.7 \%)$ & & \\
\hline Hypotention, shock & No & $2(100 \%)$ & $58(100 \%)$ & 0 & 1 \\
\hline \multirow[t]{2}{*}{ Tachycardia } & Yes & $2(100 \%)$ & $28(48.3 \%)$ & \multirow{2}{*}{$\begin{array}{c}\text { FE } \\
2.069\end{array}$} & \multirow{2}{*}{0.150} \\
\hline & No & $0(0 \%)$ & $30(51.7 \%)$ & & \\
\hline \multirow{2}{*}{ Gastrointestinal manifestations } & Yes & $0(0 \%)$ & $5(8.6 \%)$ & \multirow{2}{*}{$\begin{array}{c}\mathbf{F E} \\
.188 \\
\end{array}$} & \multirow{2}{*}{0.665} \\
\hline & No & $2(100 \%)$ & $53(91.4 \%)$ & & \\
\hline \multirow{2}{*}{ Hepatomegaly } & Yes & $0(0 \%)$ & $2(3.4 \%)$ & \multirow{2}{*}{$\begin{array}{c}\mathbf{F E} \\
0.071\end{array}$} & \multirow{2}{*}{0.789} \\
\hline & No & $2(100 \%)$ & $56(96.6 \%)$ & & \\
\hline \multirow{2}{*}{ Jaundice } & Yes & $0(0 \%)$ & $17(29.3 \%)$ & \multirow{2}{*}{$\begin{array}{c}\mathbf{F E} \\
.818\end{array}$} & \multirow{2}{*}{0.366} \\
\hline & No & $2(100 \%)$ & $41(70.7 \%)$ & & \\
\hline \multirow{2}{*}{$\begin{array}{l}\text { Neurological manifestations } \\
\text { (irritability \& hypotonia) }\end{array}$} & Yes & $2(100 \%)$ & $3(5.17 \%)$ & \multirow{2}{*}{$\begin{array}{c}\mathrm{FE} \\
0.109\end{array}$} & \multirow{2}{*}{0.741} \\
\hline & No & $0(0 \%)$ & $55(94.8 \%)$ & & \\
\hline
\end{tabular}




\section{DISCUSSION}

Neurosonography is an excellent tool for the primary neonatal brain screening. It can be easily performed at the bedside with a portable ultrasound machine. It is also cheap, radiation free and its safety

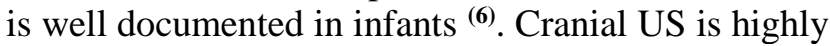
accurate for detecting intracranial hemorrhage, hydrocephalus, and cystic periventricular leukomalacia ${ }^{(7)}$. The survival of the high-risk neonate has greatly improved necessitating early detection of neurological abnormalities ${ }^{(\boldsymbol{8})}$. Transcranial ultrasound examination of newborn is typically performed with a sector transducer using $5 \mathrm{MHZ}$ or higher frequency. Standard images are obtained through two acoustic windows: anterior fontanelle (AF) and posterior fontanelle $(\mathrm{PF}){ }^{(4)}$.

This study included 60 term high-risk neonates, $39(65 \%)$ were males and $21(35 \%)$ were females. their gestational age ranged from 37 to 39 weeks (the mean was $37.78 \pm 0.83 \mathrm{w}$ ), their birth weight ranged from 2.9 to $4 \mathrm{~kg}$ (the mean was $3.16 \pm$ $0.24 \mathrm{~kg})$. CUS abnormalities were found in $2(3.3 \%)$ cases. The $1^{\text {st }}$ case was diagnosed as pneumonia and neonatal sepsis and the $2^{\text {nd }}$ case had HIE and congenital malformation.

Regarding mode of delivery in our study, 43 cases were delivered by C.S and 17 cases by normal vaginal delivery, 2 of them had US abnormalities. Kawagoe ${ }^{(9)}$ reported that no difference in neonatal and maternal outcomes in preterm regarding the mode of delivery. However, Koksal ${ }^{\left({ }^{(10)}\right.}$ reported that CS was significant protective factor against intraventricular hemorrhage (IVH). Therefore, the effect of mode of delivery is controversial.

Our study showed that $8(13.3 \%)$ of neonates were born from mothers with premature rupture of membranes (PROM). We revealed that there was no significant difference between abnormal CUS and normal CUS groups regarding perinatal risk factors (obstructed labor, and PROM. Abdelhamid et al. ${ }^{\text {(11) }}$ study on ultrasound findings as screening methods for cases admitted in NICU, Cairo University reported that $26 \%$ of neonates born of mothers with PROM had abnormal CUS findings. Zaidi and Shankar ${ }^{(12)}$ study on cranial ultrasound in high-risk neonates found that $15.4 \%$ of neonates, which had CUS abnormalities, their mothers had PROM.

Sepsis $(60 \%)$ was the most common presentation among our patients, respiratory distress (50\%), neurological manifestation (50\%), tachycardia $(50 \%)$, jaundice $(28.3 \%)$ and hypoxia $(11 \%)$. Zaidi and Shankar (12) study reported that the main complaint was respiratory distress (46\%). While, Elgebaly et al. ${ }^{(13)}$ reported that the main complaint was convulsions in $37 \%$, respiratory distress in $26 \%$, bleeding tendency in $11 \%$, apnea in $16 \%$, altered consciousness level $10 \%$ and pallor in $8 \%$ of cases.

In our study, 3 neonates were on mechanical ventilation, two of them (66.6\%) showed abnormal cranial US findings, while Elgebaly et al. ${ }^{(13)}$ found that $53.8 \%$ of neonates who were on mechanical ventilation, showed abnormal findings in US. In addition, Abdelhamid et al. ${ }^{(11)}$ found that $54 \%$ of neonates on mechanical ventilation, showed abnormal CUS findings. Khodapanahandeh et al. ${ }^{(14)}$ reported that mechanical ventilation was significantly associated with IVH. All cases of our study were fullterm, this explain why the number of cases that need mechanical ventilation were less than other studies that had preterm cases.

The cranial ultrasound findings in this study were normal in 58 cases $(96.7 \%)$ and abnormal only in 2 cases $(3.3 \%)$. We included only high-risk fullterm neonates and excluded preterm neonates. The initial cranial ultrasound abnormalities found in our study were Dandy Walker malformation (1case) and cystic leukomalacia associated with communicating hydrocephalus (1case). No IVH and no brain edema. Elgebaly et al. ${ }^{(13)}$ found that abnormal ultrasound findings were present in $61 \%$ of cases $(23 \%$ full term cases) and normal in 39\%. Abdelhamid et al. (11) found that cranial ultrasound findings in their study were abnormal in $35 \%$ of cases and normal in $65 \%$ of cases. Zaidi and Shankar ${ }^{(12)}$ found that the incidence of cranial ultrasound abnormal findings of all studied neonates was $26 \%$. This difference may be due to selection of only full-term cases in our study.

We found one case of Dandy walker malformation in our study. Danhert ${ }^{(15)}$ said that in Dandy walker malformation, transcranial ultrasound gives similar results to that of CT.

In Elgebaly et al. ${ }^{(13)}$, Mulindwa et al. ${ }^{(16)}$, Fariba et al. ${ }^{(17)}$, Mahmoud et al. ${ }^{(18)}$ and Deng et al. (19) studies, there was significant association and significant inverse correlation between gestational age in preterm groups and ultrasound findings as decrease gestational age increases ultrasound findings. Other several studies revealed that increase in gestational age is statistically protective against IVH ${ }^{(\mathbf{1 4}, \mathbf{1 0})}$. This is in agreement with our study that reported no IVH in all full term cases.

Guan et al. ${ }^{(20)}$ reported that ultrasound findings such as the size of lateral ventricles, altered brain parenchymal echogenicity and cerebral blood flow parameters are important for the early diagnosis and prognosis of HIE.

Kinkar and Dhanawade (21) reported that respiratory distress and birth asphyxia had significant 
association with abnormal ultrasound, so early cranial ultrasound could help in early intervention. Cranial ultrasonography is the best point of care neuroimaging method available for high-risk neonates. It is important investigatory method in NICU and effectively demonstrates morphology of cerebral damage ${ }^{(22)}$.

\section{CONCLUSION}

Although we found only 2 cases (3.3\%) with abnormal CUS among the studied high-risk full-term neonates, cranial ultrasound is still an excellent noninvasive tool for neonatal brain imaging especially in those presented with neurological manifestations and hypoxia. It enables screening and follow up of the brain by serial imaging. Ultrasound scanning has many advantages as portability, lack of ionizing radiation, lower cost, easily to be repeated and no need for sedation.

Acknowledgements: Authors would like to thank all neonates and their parents who participated in this study.

Sources of Support: No funding - No grants.

Conflict of Interest: No conflict of interest.

\section{REFERENCES}

1. Cowan F, Mercuri E, Groenendaal F et al. (2005): Does cranial ultrasound imaging identify arterial cerebral infarction in term neonates?. Arch Dis Child Fetal Neonatal Ed., 90 (3): 252-256.

2. Canpolat F, Yurttutans A (2011): Cranial Ultasonography in neonatal intensive care unit. Neonatologists Perspective. Medical Journal of Islamic World Academy of Sciences, 109 (430): 1-4.

3. Steggerda $S$, Leijser $L$, Walther $F$ et al. (2009): Neonatal cranial ultrasonography: How to optimize its performance. Early Hum Dev., 85 (2): 93-99.

4. Meijler G, Steggerda S (2019): Neonatal cranial ultasonography. Springer. Neonatal Cranial Ultrasonography, $\quad$ Pp: 3-6. https://link.springer.com/chapter/10.1007/978-3-31977815-0_1

5. Benson J, Bishop M, Cohen H (2002): Intracranial neonatal neurosonography: An update. Ultrasound Quarterly, 18 (2): 89-114.

6. Shankar P, Nithya S (2014): Role of Cranial Ultrasound in High Risk Neonates in NICU. Journal of Evolution of Medical and Dental Science, 3 (15): 3970-3976.

7. Bano S, Chaudhary V, Garga U (2017): Neonatal hypoxic ischemic encephalopathy. A radiological review. J Pediatr Neurosci., 12 (1): 1-6.
8. Daneman A, Epelman M (2015): Neurosonography: in pursuit of an optimized examination. Pediatr Radiol., 45 (3): 406-412.

9. Kawagoe Y (2020): Preterm birth and mode of delivery. Preterm labor \& delivery. Springer. Singapore, Pp: 117-205.

10. Koksal N, Baytan B, Bayram Y et al. (2002). Risk factors for intraventicular hemorrhage in very low birth weight infants. Indian J Pediatr., 69 (7): 561-564.

11.Abdelhamid T, Badawy N, Sheba $M$ et al. (2009): Ultrasound findings as a screening method for cases admitted in the neonatal intensive care unit. The Medical Journal of Cairo University, 15: 168-177.

12.Zaidi F, Shankar P (2011): Cranial ultrasound in high risk neonates. Rajiv Ghandi University, Bangalore. http://52.172.27.147:8080/jspui/bitstream/

123456789/7233/ 1/Dr.Fauzia\%20Zaidi.pdf

13.Elgebaly S, Mohammed H, Mansour S et al. (2014): Role of transcranial ultrasound in neonates. Zagazig University Medical Journal, 11: 121-134

14. Khodapanahandeh F, Khosravi N, Larijani $T$ (2008): Risk factors for intraventicular hemorrhage in very low birth weight infants in Tehran, Iran. Turk J Pediatr., 50: 247-252.

15.Danhert $W$ (2003): Radiology review manual. $5^{\text {th }}$ edn, chap2, William \& Wikins, Philadelphia, London, Tokyo, Pp: 173-313.

16. Mulindwa M, Sinyangwe S, Chomba E (2012): The prevalence of intraventricular haemorrhage and associated risk factors in preterm neonates in the neonatal intensive care unit at the university, teaching hospital, Lusaka, Zambia. Medical Journal of Zambia, 1: 16-21.

17.Fariba K, Nastaran K, Tahereh L (2007): Risk Factors for Intraventricular Hemorrhage in Very Low Birth Weight Infants. Iran J Ped., 17 (2): 101-107

18. Mahmoud A, Gehad S, Mohamed E (2012): Transcranial US of preterm neonates: High risk gestational age and birth weight for perinatal asphyxia. The Egyptian Journal of Radiology and Nuclear Medicine, 43 (2): 265-274.

19. Deng Y, Cao Y, Ding H (2009): Risk factors of brain damagein preterm infants hospitalized in neonatal intensive care unit. Chinese Journal of Perinatal Medicine, 12 (5): 7379.

20.Guan B, Dai C, Zhang Y et al. (2017): Early diagnosis and outcome prediction of hypoxic ischemic encephalopathy with color Doppler ultrasound. Diagnostic and Interventional Imaging, 98 (6): 469-475.

21.Kinikar U, Dhanawade S (2018): Study of cranial ultrasound its correlation with perinatal risk factors and its outcome in preterm neonates admitted to neonatal intensive care unit. Pediatric Review: International Journal of Pediatric Research, 5 (4): 169-175.

22. Nagaraj N, Berwal P, Srinivas A et al. (2016): A study of neurosonogram abnormalities, clinical correlation with neurosonogram findings, and immediate outcome of highrisk neonates in Neonatal Intensive Care Unit. J Pediatr Neurosci., 11 (3): 200-205. 